\title{
Packaging with dual information for visual and infrared spectrum
}

\author{
Denis Jurečić', Vilko Žiljak', Mensura Kudumović², Božica Kelčec Pester ${ }^{3}$ \\ ${ }^{1}$ University of Zagreb, Faculty of Graphic Arts, Croatia \\ ${ }^{2}$ University of Sarajevo, Faculty of Educational Sciences, Bosnia and Herzegovina \\ ${ }^{3}$ High school of graphic design in Zagreb, Croatia
}

\begin{abstract}
In the article is presented the design for security graphics on packaging with invisible information. The color choice is underlined by the INFRAREDESIGN ${ }^{\circledR}$ theory. Individual solutions for joining two independent images are realized with digital printing and interpreted with computer animation. Separation of the dye is performed for the default response of the hidden drawing that is released by the infrared camera. Product recognition is with IRD process as a "visual information identity". Hidden graphics are designed with a protective line solution. Experiments have been carried out in the pharmaceutical field, on the packaging of drugs. Proving the authenticity of the content is carried out by recording the packaging and comparing it with the specimen that was recorded as photographs of the twenty light blockades in the visual and infrared spectrum.

Keywords: informational identity, near infrared spectrum, design for VZ packaging, VZ separation, twins of color and colorants
\end{abstract}

\section{Hidden information in INFRAREDESIGN ${ }^{\circledast}$ processes}

The dual VIS/NIR method is a new process in printing. This paper will attempt to broaden the application and research of new methods of marking cardboard packaging, as well as improve the protection and sale of products. The information system on packaging is a dynamic one, essentially based on two opposite variables, which creates the need for optimization. Legal norms obligate the producers to state certain information on products, such as information about the harmfulness of smoking or the risk of poison, and visibly display barcodes, which take up most of the space on the box. On the other hand, the graphic, trademark and design elements have to be balanced on the remaining surface of the packaging in order to achieve a clear and recognizable packaging of the product. The textual information is more important for informing the consumer about the product. Symbols on the graphic element of the packaging serve to enhance the memorization, protection and decoration of the product. In this article, the proposal is put forth for expanding the information on the packaging of drugs into the near infrared spectrum. Reading, writing and recognizing such data are performed with infrared cameras which the authors have developed over the past years [1]. A large number of security cameras have been set up in banks, schools, streets, restaurants, shops and private areas [2]. Information with hidden graphics can be found on clothes, ranging from military uniforms to the application in fashion on dresses in the textile industry [3]. The expanded information system with the INFRAREDESIGN ${ }^{\circledR}$ has found its application in the packaging of labels of new products, creating a new marketing system and a new way of informing customers, as well as a new way of protecting products [4], [5]. Hidden images with near infrared technology are expanded not only into the area of design, but also into the area of fine art [6]. The insisting 
on the precision of the duality visible/invisible has opened a new area in the study of colors and colorants through spectral analyses of light absorption in the range between 400 and 1000 nanometers [7]. For printing with twins of colors in the graphic industry, the method of the spectroscopy of each component of the process and the method of joint imprint are suggested [8]. The IDR procedure of expanded information is applied on packaging of various materials. An example of a successful concealment is the work on transparent polypropylene [9]. Double information on the same spot and mutual concealment are our topic on "infrared design" of information on drug packaging. In the interest of the safety of the graphic solution, the name of the pharmaceutical company and the name of the drugs are not disclosed in reality.

\section{Design of packaging with hidden dual information}

Experimental printing has included digital printing procedures. New color settings for toner printing which have not been published in earlier papers have been used. New twins of color and colorants for printing on cardboard have been experimentally determined. The results of the research have been collected in the new regression model of dependency X40 of the mixtures of colorants on the initial tones $\mathrm{X} 0$. The forensic system of hiding information in conventional printing techniques has been expanded. The application of INFRAREDE$\mathrm{SIGN}^{\circledR}$ is directed toward creating an informational identity for new products in the pharmaceutical industry. Here is presented a collection of boxes which represent a group of products with the three-letter extension (or prefix) "NIR". This is an abbreviation for "near infrared", which suggests a design component in the dual description of the product name. The identity of this collection of packaging is based on twins of colors and colorants, which carry the information on the absorption of light in two light spectra. The choice of colors is subordinated to the stochastic algorithm within limitations; each process component of the twins of color designated for the visual spectrum is larger than $40 \%$ of the coverage.
The dependency of the coverage of process colorants for digital print OKI ES5431 on paper heavier than $200 \mathrm{gr} / \mathrm{kg}$ has been experimentally determined. Table 1 shows the values for the default coverage of $40 \%$ for the carbon black colorant. Values $\mathrm{X} 0$ are the initial values $\mathrm{C}, \mathrm{M}, \mathrm{Y}$ with $\mathrm{K}=0 \%$. With the presence of the carbon black colorant (40\%-GCR substitution) ideal values for the process colorants (X40) C, M, Y (marked as C40, M40, Y40) have been adjoined. The default value of the carbon black colorant $\mathrm{K}$ of $40 \%$ is an idea and a difference compared to the general settings of the process of separation according to the GCR method. We say that VZ separation is a "special form" of GCR separation. Due to the firm limit (40\%) for all color tones, a high precision of the calculation of X40 is required. Our eyes will see an aberration greater than ca $3 \%$ of the coverage of each process component. In such print, the "hidden image Z" starts tobe visible and recognizable. In real applications of the general GCR method, such precision is not required because there is no intention to observe the black colorant or the graphic component with a NIR camera.

The criterion for the selection of the system of colorants includes measuring after experimental printing: DeltaE $<3$. The experimental design for two colorants X40 and X0 is planned with a straight contact, vertical and horizontal. With inadequate twins, our eyes can see these contacts. The direction of the modification and finishing of the composition of the components is determined with spectrography [10].

Experiments have been conducted with 220 colorants. The parameters of the linear equation of dependency of X40 on X0 have been calculated with regression analysis. The values of coverage of 12 dyes of different color tones are shown in table 1 and the corresponding values have been calculated, marked as $\mathrm{Cr}$, $\mathrm{Mr}, \mathrm{Yr}, \Delta \mathrm{C}, \Delta \mathrm{M}, \Delta \mathrm{Y}$. The deviations are smaller than $3 \%$, which encourages us to use the twins according to equation (1) for a whole range of colors of very complex design. Table 1 is the control for the correctness of work of some future program for digital print with dry toner.

Table 1 shows the $\Delta \mathrm{X}$ deviation of measured values of $\mathrm{X} 40$ from the calculated values $\mathrm{Xr}$. This is the first indicator that the colorant is 
Table 1. Twins of color for print on cardboard

\begin{tabular}{|r|r|r|r|r|r|r|r|r|r|r|r|}
\hline \multicolumn{4}{|c|}{ X0 (\%) } & \multicolumn{6}{c|}{ X40, experimentally and regression Xr and difference in deviation $\Delta \mathrm{X}$} \\
\hline $\mathrm{C} 0$ & \multicolumn{1}{|c|}{$\mathrm{M} 0$} & $\mathrm{Y} 0$ & $\mathrm{C} 40$ & $\mathrm{Cr}$ & \multicolumn{1}{c}{$\Delta \mathrm{C}$} & $\mathrm{M} 40$ & $\mathrm{Mr}$ & $\Delta \mathrm{M}$ & $\mathrm{Y} 40$ & \multicolumn{1}{c|}{$\mathrm{Yr}$} & $\Delta \mathrm{Y}$ \\
\hline 51 & 99 & 58 & 15 & 16.31632 & -1.31632 & 70 & 68.33224 & 1.667759 & 15 & 17.8318 & -2.8318 \\
\hline 64 & 99 & 74 & 25 & 28.18895 & -3.18895 & 61 & 59.93576 & 1.064243 & 33 & 34.80921 & -1.80921 \\
\hline 61 & 99 & 64 & 25 & 26.33442 & -1.33442 & 64 & 63.16032 & 0.83968 & 20 & 23.37075 & -3.37075 \\
\hline 63 & 99 & 84 & 26 & 25.69939 & 0.300609 & 58 & 58.29031 & -0.29031 & 46 & 46.89358 & -0.89358 \\
\hline 66 & 99 & 89 & 29 & 28.25569 & 0.74431 & 56 & 56.08586 & -0.08586 & 51 & 52.3706 & -1.3706 \\
\hline 69 & 99 & 73 & 31 & 33.75942 & -2.75942 & 58 & 58.16589 & -0.16589 & 31 & 32.80953 & -1.80953 \\
\hline 80 & 51 & 99 & 47 & 50.25684 & -3.25684 & 0 & -0.05807 & 0.058074 & 62 & 62.6984 & -0.6984 \\
\hline 49 & 99 & 44 & 16 & 16.10923 & -0.10923 & 74 & 71.97812 & 2.021883 & 0 & 1.4627 & -1.4627 \\
\hline 63 & 99 & 74 & 26 & 27.10293 & -1.10293 & 60 & 60.33054 & -0.33054 & 37 & 34.97069 & 2.029311 \\
\hline 85 & 99 & 49 & 53 & 54.50429 & -1.50429 & 57 & 56.74598 & 0.254019 & 0 & 1.610933 & -1.61093 \\
\hline 58 & 99 & 72 & 22 & 21.95352 & 0.046477 & 63 & 62.71247 & 0.287527 & 31 & 33.3935 & -2.3935 \\
\hline 70 & 99 & 89 & 33 & 32.59978 & 0.400217 & 54 & 54.50674 & -0.50674 & 51 & 51.72468 & -0.72468 \\
\hline
\end{tabular}

not a quality mixture. Spectroscopy will give the direction of the adjustment since the graph of the light absorption in the visual spectrum can show the necessary increase or reduction of an individual process component [8].

$\mathrm{C} 40=-0.1403{ }^{\star} \mathrm{Y}-0.1708^{\star} \mathrm{M}+1.086^{\star} \mathrm{C}-14.02$

$\mathrm{M} 40=-0.2040 * \mathrm{Y}+1.012{ }^{\star} \mathrm{M}-0.3948^{\star} \mathrm{C}+0.11$

$\mathrm{Y} 40=1.1923^{\star} \mathrm{Y}-0.0138^{\star} \mathrm{M}-0.1615^{\star} \mathrm{C}-41.71$

Model of VZ separation: $\mathrm{Xr}=\mathrm{f}(\mathrm{X} 0)$ for $\mathrm{X} 40$

Real print for the GCR procedure has included the material, the toner and paper properties and the method of printing. The values of parameters in equations (1) show that every color X40 depends on the remaining three colors from the X0 setting. However, the expected parameters result in values along a diagonal, in contrast with the conventional understanding of the GCR method, where they should have the value equaling 1 . The remaining parameters would equal zero. In our model the other parameters are treated as "corrections" due to the properties of the material and toner.

The algorithms and programs for VZ separation conduct the calculation of all other colorants with the values of components $\mathrm{C}, \mathrm{M}, \mathrm{Y}$ of the twins $\mathrm{Xr}$ according to the relation (1). Each colorant in the visual and NIR design is assigned its $\mathrm{Xr}$ value, regardless of whether or no this colorant has been in the experiment for the determination of its twin on the position $\mathrm{X} 40$.

\section{Design of the new identity for PHARMANIR}

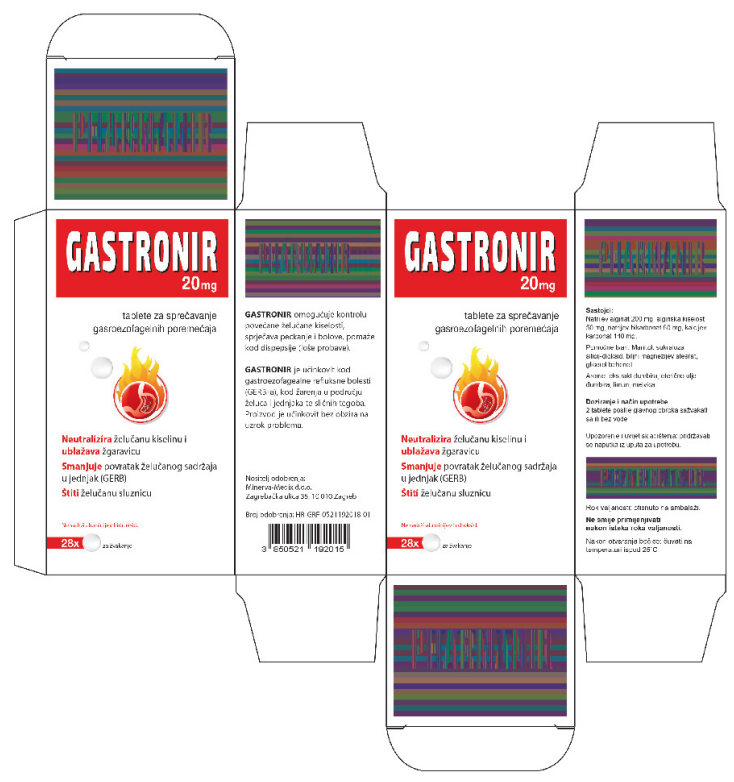

Figure 1. Packaging of the drug GASTRONIR

A typical drug in the daily collection is GASTRONIR. The name is recognized in two spectra (image 1 and 2). The same goes for the instructions for use and the description of the content of the drug. Dual information contains the name of the pharmaceutical house 
PHARMANIR. The text is recognized in the visual spectrum and is designed as line graphics. Each color of the individual line has its twin in the NIR spectrum. These twins of color have offered the information "NIRIDON" and the suitable name for the conference, "Blaž Baromić". Carbon black color has been added to the information reader with EAN codes in order for it to be recognized by cameras for the visual and NIR spectrum.

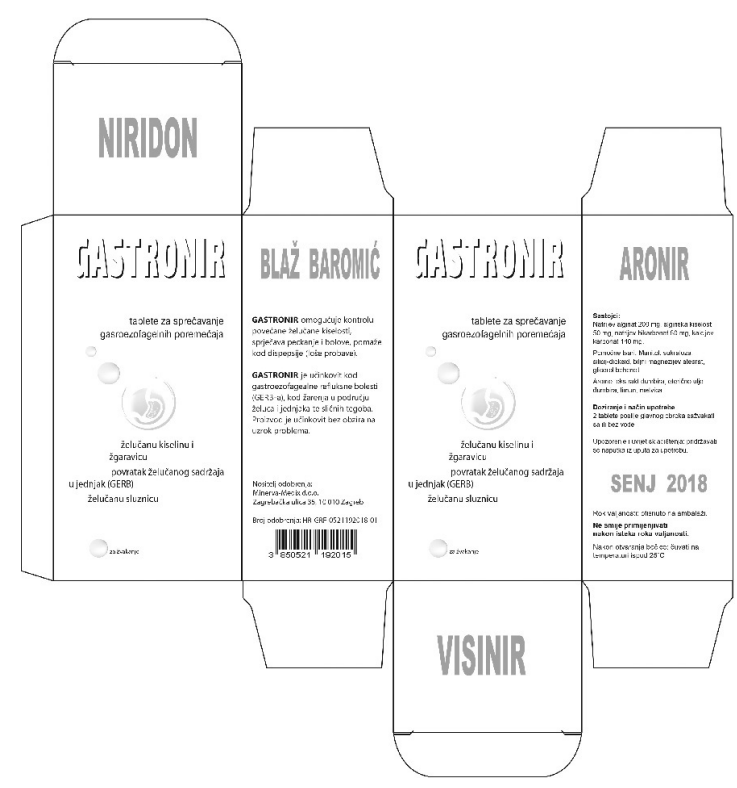

Figure 2. Packaging GASTRONIR, near infrared spectrum at $1000 \mathrm{~nm}$

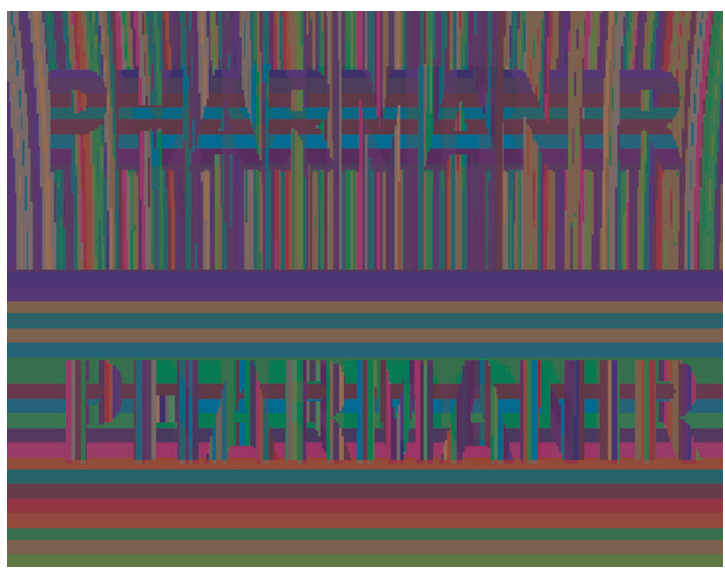

Figure 3. Detail of the visual design of the company PHARMANIR

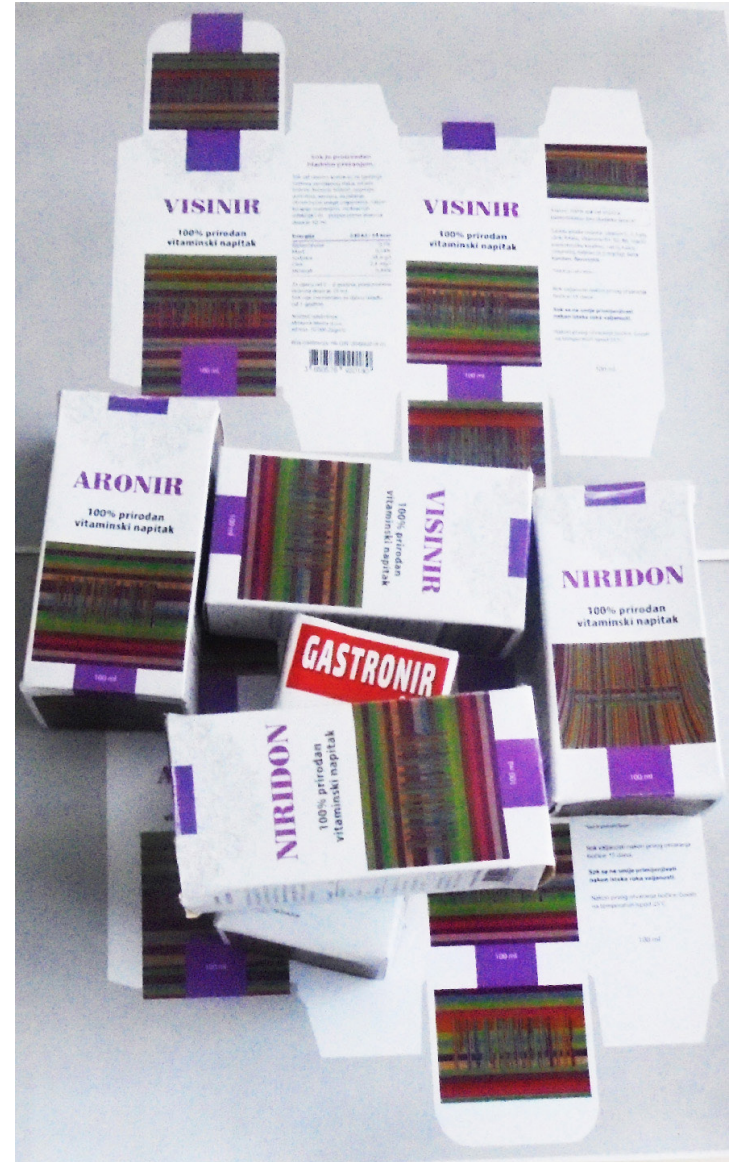

Figure 4. Packaging for the collection of drugs PHARMANIR

The packaging for drugs for the pharmaceutical company PHARMANIR was designed for the Conference "Blaž Baromić" in Senj 2018, with protective IRD line structure. The four drugs ARONIR, NIRIDON, VISINIR and GASTRONIR have in common the emphasis on the display of text (image 4). Visually, there is no appropriate information about the conference or about where it takes place. The industry Pharmanir's visual idenity is the same as that of other collections of drugs.

The emphasis on the name of the conference, which cannot be seen with the naked eye (image 4), is left for the near infrared spectrum (image 5). The name of the city where this dual design is published is added in the NIR spectrum - "SENJ 2018". In the infrared spectrum, the name of the drug (the first three) is recognized with a ZRGB camera [1] only on the lid of the packaging. The colors $\mathrm{X} 0$ in the design of the lines are chosen randomly. Because of the stochastic approach to the selection of colors, 
X40 has to be mathematically determined (1). None of the colors comes from the palette of measurements of the dual twins. This is also a test for the use of unrestricted, continuous palette of colors for digital print on cardboard according to the method of VZ separation.

The design of the drug packaging was photographed with a forensic camera [9] Projektina, model PAG 50. Twenty-two photographs were produced after printing. The corresponding filters are between 400 and $1000 \mathrm{~nm}$. The sequence of photographs has been joined in an animation for display. In this paper the design of the part of packaging with dual information for the "drugs" VISINIR and NIRIDON is shown.

This kind of imprint on drug packaging is a special feature and a guarantee for the buyer that the product inside the packaging is original, which is especially important for Internet purchase.

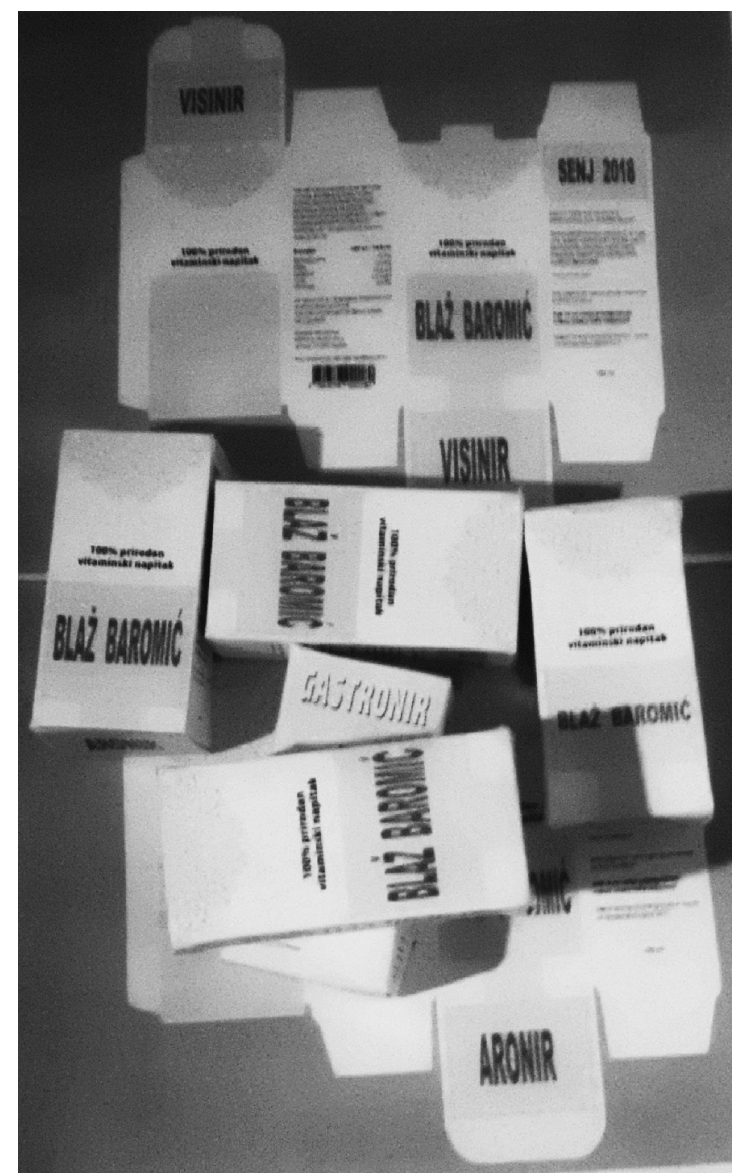

Figure 5. Packaging of PHARMANIR drugs recorded with a filter at $1000 \mathrm{~nm}$

\section{Conclusion}

The forensic system of invisible protection of information on packaging with conventional printing techniques is expanded. The programming of the dependency of images in two spectra is enabled through experimental work on determining the pairs of twins of colors and colorants. The dual design is based on the mathematical description of the relation between the visual and near infrared spectrum. The relations of the VZ separation of colors as a special form of the GCR method are determined through regression analysis. The offered new VZ separation will be applied in other designs of cardboard packaging. The double, hidden, invisible information is an expansion in the area of safety graphics. New research in the area of VZ design includes materials such as silk, leather, ceramics and textiles in general.
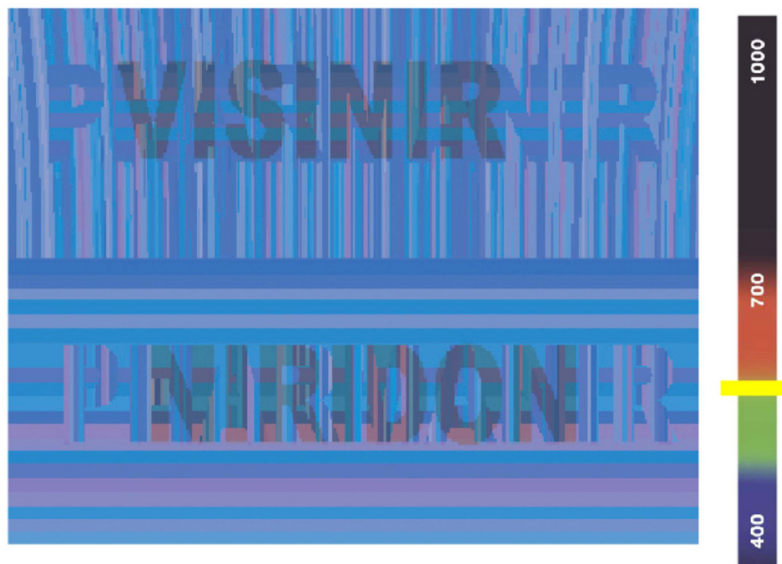

Figure 6. Animation of light blocade: $\underline{\text { http:// }}$ vilko.ziljak.hr/visinir.mp4 


\section{References}

[1] Žiljak,V, Pap, K, Žiljak-Stanimirovic, I: Development of a prototype for ZRGB infraredesign device. // Technical Gazette. 18 (2011) , 2; p:153-159

[2] Ivan Rajkoviæ, Vilko Žiljak; Usage of ZRGB video camera as a detection and protection systemand development of invisible infrared design; Polytechnic \& Design; Zagreb University of applied sciences; Vol. 4, No. 1, 2016. pp: 54 - 59; ISSN 2459-6302; ISSN ;1849-1995 ; DOI: 10.19279/TVZ.PD.2016-4-1-07

[3] Ivana Z. Stanimirovic, Jana Z. Vujic, Nikolina Stanic Loknar; Marking of the camouflage uniform for visual and near infrared spectrum, TTEM, Technics Technologies Education Management, Vol 8. No3. 2013, p: 920 - 026, ISSN 1840-1503

[4] Darija Ćutić, Denis Jurečić, Branka Morić, Sanja Bjelovučić Kopilović, Sigurnosni infracrveni dizajn slika portreta na modnoj odjeći, Safety infrared design of a portrait pictures on a fashion clothing, Polytechnic \& Design, Vol. 6, No. 2, 2018, p:118 - 122, DOI: 10.19279/TVZ.PD.2018-6-2-06

[5] Branka Moric Kolaric, Mirna Grgić, Denis Jurečić, Pero Miljković: Sigurnosna etiketa soka od aronije skanirana u blokadama u bliskom infracrvenom spektru, Polytechnic\&Design, Vol 5. No 4, p:280-286; 2017; DOI: 10.19279/TVZ.PD.2017-5-4-12
[6] V. Žiljak, L. Tepeš Golubic, D Jurecic, J. Žiljak Gršic; Double image with ceramic colors in the process of infrared painting, International Journal of Applied Physics; ISSN: 2367-9034 82; Volume 2, pp 18-23, 2017 http://www.iaras.org/iaras/journals/ijap

[7] Aleksandra Bernašek Petrinec, Jana Žiljak Gršic, Sanda Stanacev Bajzek; infrared painting in fine art of Nada Žiljak, 5th International Multidisciplinary scientific conference on social science \& arts, SGEM 2018, Conference proceedings pp:391-396, Vol.5, Science and art, Issue 6.1/ Contemporary arts, ISBN 978-619-7408-34-8 ISSN 2367-5659 DOI: 10.5593/ sgemsocial2018H/61

[8] Jana Žiljak Gršić; Near infrared spektroskopy in print tehnology; Polytechnic \& Design, Vol. 5, No. 1, 2017. pp:32-36; DOI: 10.19279/TVZ.PD.2017-5-1-05

[9] Jana ŽILJAK, Denis JURECIC, Vilko ŽILJAK, Packaging Design with Hidden Near Infrared Colour Separation, Tehnicki vjesnik/Technical gazette, Vol.25 No.3 pp: 211-215, 2018. ISSN 1330-3651 (Print), ISSN 1848-6339 (Online), https://doi.org/10.17559/ TV-20170705114921

[10] Docucenter 4500 \& PAG B50, http://forensictechnology.com/projectina/ Projectina AG, Switzerland, 